\title{
OBSERVATORIO DE RIESGOS: NUEVOS RIESGOS BIOLÓGICOS EN EL LUGAR DE TRABAJO
}

26 de noviembre de 2007.- En su nuevo informe, el Observatorio Europeo de Riesgos señala algunos de los riesgos biológicos emergentes que tienen más probabilidades de afectar a los trabajadores de la UE, especialmente a los agricultores, al personal sanitario o a las personas que trabajan en sectores en evolución, como el del tratamiento de residuos. Las enfermedades transmisibles, como el SRAS, la gripe aviar o el dengue, son especialmente preocupantes. A pesar de la legislación europea adoptada, aún se conoce poco sobre estas amenazas y en muchos lugares de trabajo los riesgos biológicos no se analizan ni se previenen adecuadamente. El informe hace hincapié en la importancia de adoptar un enfoque global y multidisciplinario en relación con la salud y la seguridad en el trabajo, la salud pública, la protección medioambiental y la seguridad alimentaria.

Según Jukka Takala, Director de la Agencia Europea para la Salud y la Seguridad en el Trabajo, de la que forma parte integrante el Observatorio Europeo de Riesgos, "los riesgos biológicos a menudo se subestiman, aunque pueden ser muy elevados para los trabajadores de la UE prácticamente de cualquier sector". "Es preciso identificarlos rápidamente cuando aparecen, analizar sus posibles consecuencias para la salud de las personas y elaborar políticas y procedimientos para reducir al mínimo su difusión". Las previsiones de los expertos del Observatorio identifican riesgos biológicos nuevos y en aumento en relación con la seguridad en el trabajo y subrayan la importancia de tener en cuenta todas las responsabilidades y medios de control colectivos, tanto dentro como fuera del lugar de trabajo.

\section{LAS ENFERMEDADES TRANSMISIBLES AMENAZAN A LOS TRABAJADORES DE LA UE}

Se calcula que 320.000 trabajadores de todo el mundo fallecen anualmente debido a enfermedades transmisibles causadas por riesgos biológicos repre- sentados por virus, bacterias, insectos u otras especies animales. Aunque la mayor parte de las muertes se producen en países en desarrollo, unos 5000 trabajadores son víctimas de estas enfermedades en la UE. Las mujeres son más propensas a contraerlas que los hombres, puesto que ocupan puestos de trabajo con un nivel de riesgos biológicos y de exposición más elevado.

La mayoría de los riesgos emergentes están relacionados con epidemias mundiales causadas por nuevos microorganismos patógenos, como los causantes del síndrome respiratorio agudo severo (SRAS), la gripe aviar y el ébola, sin olvidar la reaparición de otros riesgos como el cólera y la fiebre amarilla. Dada la velocidad y el volumen del tráfico y el comercio internacionales, estos patógenos se pueden propagar en todo el mundo en unas pocas horas y desatar una nueva pandemia.

\section{SECTORES CON MAYOR RIESGO}

Como muchas de estas enfermedades saltan las barreras de las especies y se transmiten de los animales a los seres humanos, los trabajadores en contacto con el ganado están

especialmente expuestos al riesgo. Otros patógenos como la tuberculosis se han hecho más resistentes a los fármacos conocidos y pueden causar infecciones graves entre el personal sanitario.

Pueden producirse situaciones de exposición complejas en sectores nuevos, como el del tratamiento de residuos, en el que los trabajadores entran en contacto con una serie de microorganismos y compuestos orgánicos que se transmiten por el aire. Los mohos se pueden propagar en los lugares de trabajo debido a un mantenimiento deficiente del aire acondicionado, con el riesgo consiguiente de asma y alergias. 


\section{SEGUNDO INFORME SOBRE RIESGOS EMERGENTES}

El informe del Observatorio Europeo de Riesgos es el segundo de una serie dedicada a los riesgos emergentes. Los resultados de sus previsiones, junto con los tres trabajos complementarios sobre los riesgos físicos, químicos y psicosociales, constituyen únicamente el primer paso en un proceso de debate y consolidación que forma parte del programa de trabajo de la Agencia.

\section{OTRAS LECTURAS}

Descarga gratuita de los informes sobre riesgos emergentes

- Hoja informativa sobre riesgos biológicos emergentes.

Disponible en: [English] [Español] [Français]
- Previsiones de expertos sobre los riesgos biológicos emergentes relacionados con la seguridad y la salud en el trabajo. Disponible en: [English].

- Previsiones de expertos sobre los riesgos físicos emergentes relacionados con la seguridad y la salud en el trabajo Disponible en: [English].

- Observatorio Europeo de Riesgos

- DIRECTIVA 2000/54/CE del Parlamento Europeo y del Consejo, de 18 de septiembre de 2000, sobre la protección de los trabajadores contra los riesgos relacionados con la exposición a agentes biológicos durante el trabajo. 